\title{
Estratégias didáticas de professores no Ensino Remoto Emergencial (ERE) frente à pandemia da Covid-19: novos desafios, outros aprendizados
}

\author{
Teaching Strategies for Teachers in Emergency Remote Teaching (ERE) in the Face of the \\ Covid-19 Pandemic: New Challenges, Other Learning
}

\section{Estrategias didácticas para docentes en teleenseñanza de emergência (ERE) ante la pandemia Covid-19: nuevos retos, otros aprendizajes}

\author{
Carloney Alves de Oliveira ${ }^{1}$ \\ Joenneyres Raio de Souza Amancio²
}

\begin{abstract}
Resumo
O presente artigo propõe uma reflexão acerca de estratégias didáticas utilizadas por professores do estado de Alagoas frente ao contexto pandêmico causado pelo novo coronavírus no Ensino Remoto Emergencial (ERE), mediado, especialmente, pelas tecnologias digitais (TD). Este estudo toma como base autores que discutem sobre TD, ERE e desafios à educação, a partir de artigos e vídeos já socializados em periódicos, internet, sites e redes sociais. Trata-se de um estudo de cunho qualitativo numa abordagem exploratória. Para tanto, os dados foram coletados a partir de um questionário online disponibilizado em rede para os professores do estado. Participaram desta pesquisa 21 professores que atuam no Ensino Fundamental, anos iniciais e finais, e do Ensino Médio, distribuídos em instituições públicas e/ou privadas de 8 cidades alagoanas. Os resultados evidenciam que as TD em si não promovem a produção do conhecimento nem o aprendizado, pois é preciso uma reconfiguração de estratégias didáticas para a potencialização da interação entre os sujeitos envolvidos no processo de ensino e aprendizagem, de maneira a compreender que as vivências com o ERE podem dar um impulso para se pensar essa prática mediada pelas TD, mas também possibilidades para além delas.
\end{abstract}

Palavras-chave: Estratégias didáticas; Ensino Remoto Emergencial; Covid-19.

\begin{abstract}
This article proposes a reflection on teaching strategies used by teachers in the state of Alagoas in the context of the pandemic caused by the new coronavirus in emergency remote education (ERE), mediated, especially, by digital technologies (TD). This study is based on authors who discuss TD, emergency remote teaching and challenges to education, from articles and videos already socialized on the internet, through websites and social networks. This is a qualitative

\footnotetext{
${ }^{1}$ Pós-Doutor em Educação, Universidade Federal de Sergipe - UFS. Doutor em Educação, Universidade Federal de Alagoas - UFAL. Professor do Centro de Educação, UFAL, atuando no curso de Pedagogia, e nos programas de pós-graduação em Ensino de Ciências e Matemática (PPGECIM/UFAL), Ensino (RENOEN/UFAL) e Educação (PPGE/UFAL). Líder do Grupo de Estudos e Pesquisas em Tecnologias Educativas e Práticas Pedagógicas em Educação Matemática (GPTPEM/AL). Maceió/AL. E-mail: carloneyalves@gmail.com. ORCID: https://orcid.org/0000-0002-2134-0587.

${ }^{2}$ Doutorando em Ensino, Universidade Federal de Alagoas - UFAL. Mestre em Ensino de Ciências e Matemática, Universidade Federal de Alagoas - UFAL. Membro do Grupo de Estudos e Pesquisas em Tecnologias Educativas e Práticas Pedagógicas em Educação Matemática (GPTPEM/AL). Maceió/AL. E-mail: rd-raio@hotmail.com. ORCID: https://orcid.org/0000-0002-4395-3384.
} 


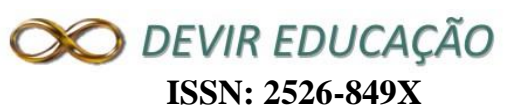

study in an exploratory approach. For this purpose, data were collected from an online questionnaire made available on the network to teachers in the state. Twenty-one teachers who work in Elementary School, initial and final years, and High School, distributed in public and/or private institutions in 8 cities in Alagoas participated in this research. The results show that the technologies themselves do not promote the production of knowledge or learning, as a reconfiguration of didactic strategies is needed to enhance the interaction between the subjects involved in the teaching and learning process, in order to understand that the experiences with emergency remote education can provide an impulse to think about this practice mediated by TD, but also possibilities beyond them.

Keywords: Didactic strategies; Emergency Remote Learning; Covid-19.

\section{Resumen}

Este artículo propone una reflexión sobre las estrategias de enseñanza utilizadas por los docentes del estado de Alagoas en el contexto de la pandemia provocada por el nuevo coronavirus en la educación remota de emergencia, mediada, especialmente, por tecnologías digitales (TD). Este estudio se basa en autores que discuten la TD, la teleeducación de emergencia y los desafíos a la educación, a partir de artículos y videos ya socializados en Internet, a través de sitios web y redes sociales. Se trata de un estudio cualitativo con enfoque exploratorio. Para ello, se recopilaron datos de un cuestionario en línea disponible en la red para docentes del estado. En esta investigación participaron veintiún profesores que laboran en la Escuela Primaria, primer y último año, y Bachillerato, distribuidos en instituciones públicas y / o privadas en 8 ciudades de Alagoas. Los resultados muestran que las tecnologías en sí mismas no promueven la producción de conocimiento o aprendizaje, ya que se necesita una reconfiguración de estrategias didácticas para potenciar la interacción entre los sujetos involucrados en el proceso de enseñanza y aprendizaje, a fin de comprender que las experiencias con emergencias remotas La educación puede dar un impulso a pensar en esta práctica mediada por la TD, pero también en posibilidades más allá de ellas.

Palabras clave: Estrategias didácticas; Aprendizaje remoto de emergencia; COVID-19.

\section{Introdução}

O desafio de fazer pesquisa em educação e tecnologias digitais (TD) no contexto da pandemia nos remete a reflexões sobre as possibilidades e potencialidades que esse binário possui para produzir significados nos processos de ensino e de aprendizagem, dentro e fora da escola, para a reorganização de estratégias didáticas relativas às mudanças curriculares, buscando encarar desafios, numa construção coletiva de conhecimento científico (BORBA, 1999). 


\section{Q DEVIR EDUCAÇÃO \\ ISSN: 2526-849X}

As TD no contexto de sala de aula em tempos de Covid $-19^{3}$ podem ser utilizadas nos processos formativos como atribuição de sentido ao processo educativo e à produção de significados no contexto da cultura contemporânea, a cibercultura. De acordo com Santos (2014) a cibercultura é considerada como a cultura contemporânea mediada pelo digital em rede na tessitura entre a cidade e o ciberespaço, e a forma como lidamos, tratamos e interagimos na contextualização e na produção de sentidos, autorias e práticas de docência e formação.

A propagação acelerada da Covid-19 tem exigido medidas importantes por parte dos governantes brasileiros e de todo o mundo, visando ao enfrentamento, adaptação e prevenção da doença em todos os âmbitos da vida humana, inclusive na educação. As consequências, impactos e implicações sobre a sociedade são significativos e ainda não foram dimensionados na sua totalidade. A suspensão das aulas presenciais, no ensino básico e superior, pela urgência de se estabelecer o distanciamento social, tem se constituído como solução mais urgente para proteger alunos e profissionais da educação, reduzindo as chances de que se tornem transmissores do vírus em suas famílias e comunidades (OLIVEIRA; SILVA; SILVA, 2020).

Além de provocar mudanças no âmbito educacional, associada aos contextos de mobilidade e ubiquidade, entendemos ainda que a cibercultura potencializa as práticas pedagógicas e os espaços formativos a partir de fundamentos que valorizem a autonomia, o diálogo, a pluralidade e as interações sociais, pois para Lemos (2002, p. 131), a cibercultura é uma forma "[...] sociocultural que emerge da relação simbiótica entre a sociedade, a cultura e as novas tecnologias de base macroeletrônicas.”. Na mesma linha de pensamento, Santaella (2003, p.77) entende que a cultura contemporânea é formada a partir de um complexo de redes em "[...] imbricamento de diferentes lógicas comunicacionais em um mesmo espaço social.”.

Deste modo, neste artigo defendemos o argumento de que as tecnologias digitais no contexto da pandemia podem ser utilizadas como um catalisadoras de uma mudança no paradigma educacional, que promovam a aprendizagem ao invés do ensino, que coloquem o controle do processo de aprendizagem nas mãos do aprendiz, na perspectiva da mobilidade e ubiquidade (SANTAELLA, 2010), objetivando refletir acerca de estratégias didáticas utilizadas por professores do estado de Alagoas frente ao contexto pandêmico causado pelo novo coronavírus no ensino remoto emergencial, mediado, especialmente, pelas TD. Isso auxilia o

\footnotetext{
${ }^{3} \mathrm{O}$ site https://coronavirus.saude.gov.br/ conceitua a Covid-19 como uma doença causada pelo coronavírus SARS-CoV-2, que apresenta um quadro clínico o qual varia de infecções assintomáticas a quadros respiratórios graves, podendo necessitar de suporte para o tratamento de insuficiência respiratória (suporte ventilatório).
}

Revista Devir Educação, Lavras-MG. Edição Especial, p.323-340, Set./2021. 


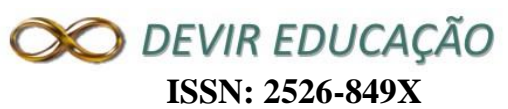

professor a entender que a educação não é somente a transferência da informação, mas um processo de construção do conhecimento do aluno, como produto do seu próprio engajamento intelectual ou do aluno como um todo.

Para evidenciar tais considerações, neste texto, inicialmente, problematizamos a concepção das tecnologias digitais em tempos de Ensino Remoto Emergencial (ERE). Em seguida, evidenciamos o delineamento da pesquisa e quais estratégias didáticas foram utilizadas pelos sujeitos envolvidos de oito municípios alagoanos e seus desafios e por fim, discutimos algumas considerações acerca das TD e do estudo relatado.

\section{Tecnologias Digitais (TD) em tempos de Ensino Remoto Emergencial (ERE): possibilidades e aprendizados}

O potencial pedagógico das TD em tempos de ERE permite e oferece aos seus usuários acesso à informação, conversação com os sujeitos envolvidos e a liberdade de navegabilidade em tempo e espaço, possibilitando, de forma integrada, o desenvolvimento de tarefas, veiculação de dados, ajustes às necessidades e aos objetivos de cada curso, na organização, reorganização e flexibilização curricular, a fim de atender às novas exigências para a construção do conhecimento sistematizado, que instiguem à investigação e à curiosidade do sujeito em formação.

O emprego das TD como recurso educacional possibilita aos professores e alunos, resolver problemas, construir e buscar conhecimento, criando um ambiente desafiador e aberto ao questionamento, capaz de instigar a curiosidade e criatividade desses sujeitos.

As TD no contexto da pandemia podem ser utilizadas como um catalisador de uma mudança no paradigma educacional, que promovam a aprendizagem ao invés do ensino, que coloquem o controle do processo de aprendizagem nas mãos do aprendiz. Isso auxilia o professor a entender que a educação não é somente a transferência da informação, mas um processo de construção do conhecimento do aluno, como produto do seu próprio engajamento intelectual ou do aluno como um todo.

Nessa concepção, os usuários de ambientes tecnológicos devem ser encorajados a confrontar-se com a realidade e a ser criativos em prol de novas descobertas e alternativas inovadoras mediante o desafio de educar numa "sociedade em rede" que segundo Castells (1999), a relação crescente entre máquinas e homem está alterando o modo pelo qual nascemos, 


\section{Q DEVIR EDUCAÇÃO \\ ISSN: 2526-849X}

trabalhamos, produzimos e vivenciamos uma revolução tecnológica centrada nesses ambientes, a qual favorece a criação de novas formas e canais de comunicação.

De acordo com Valente (2004), as TD na educação têm sido utilizadas tanto para ensinar sobre computação como para ensinar praticamente qualquer assunto, constituindo-se em alternativas inovadoras para a geração de situações de aprendizagem mais coerentes com o perfil atual.

O desenvolvimento e a utilização de TD complementares ao ERE permitem a movimentação, colaboração, socialização, integração e conexão das pessoas com o mundo, para o mundo e no mundo, potencializando assim as práticas educacionais alterando hábitos, valores e modos de pensar e de aprender com tais recursos.

As mudanças introduzidas pelas TD podem contribuir para o enriquecimento progressivo dos ambientes e contextos de aprendizagem, convidando o professor a ampliar e reformular suas práticas pedagógicas, para que os alunos possam escolher novos caminhos, visto que a produção do conhecimento está associada à ideia de construção conjunta.

As TD têm o computador conectado à internet como instrumento principal da integração e podem favorecer o processo de ensino e de aprendizagem, revelando possibilidades de criação dialógica propiciada pelas interações de pensamentos, conceitos, imagens, mídias e ideias, nas quais o sujeito atua de forma consciente com os objetos do conhecimento, pois conforme Valente (2007, p. 38),

[...] o processo ensino-aprendizagem deve incorporar cada vez mais o uso das tecnologias digitais para que os alunos e os educadores possam manipular e aprender a ler, escrever e expressar-se usando essas novas modalidades e meios de comunicação, procurando atingir o nível de letramento.

Com as TD no contexto da pandemia, professores e alunos precisam ser muito flexíveis e criativos na valorização da construção coletiva, da criatividade, da aprendizagem através da imagem, do audiovisual, das trocas, da constante interação, privilegiando, além do cognitivo, o afetivo e o intuitivo, para potencializar estratégias didáticas que estabeleçam relações que possam contribuir para a constituição de um conhecimento coletivo, levando o sujeito a atitudes de criação e autoria, acompanhando cognitivamente o processo de aprendizagem objetivado. Todavia, para a autonomia do aprendiz é cada vez mais urgente e necessário desencadear elementos que estabeleçam conexões com a diversidade de ritmos, disponibilidades, interesses e 


\section{Q) DEVIR EDUCAÇÃO \\ ISSN: 2526-849X}

a multiplicidade de tarefas de cada usuário, pois segundo Almeida e Valente (2011, p. 36), as TD podem

[...] potencializar as práticas pedagógicas que favoreçam um currículo voltado ao desenvolvimento da autonomia do aluno na busca e geração de informações significativas para compreender o mundo e atuar em sua reconstrução, no desenvolvimento do pensamento crítico e auto-reflexivo do aluno, de modo que ele tenha capacidade de julgamento, auto-realização e possa atuar na defesa dos ideais de liberdade responsável, emancipação social e democracia.

Para que estes momentos de comunicação e expressão sejam concretizados, necessita-se de sujeitos ativos, criativos, críticos e autônomos. Pensar criticamente e agir criativamente é dominar conhecimentos específicos, além de problematizar e facilitar o desenvolvimento de competências e habilidades necessárias para se atuar na sociedade em rede, com o uso de diferentes mídias, linguagens e tecnologias, tais como

vídeo, TV digital, imagem, DVD, celular, Ipod, jogos, realidade virtual, que se associam para compor novas tecnologias. Nesse caso a tecnologia digital ao associar-se com as telecomunicações incorporou a internet com os recursos de navegação, envio e recebimento de textos, imagens, sons e vídeos. (ALMEIDA, 2004, p. 36)

Estas tecnologias podem otimizar o trabalho de sala de aula e mobilizar a socialização de saberes e a construção de sentidos no processo de ensino e de aprendizagem, reforçando a rápida e eficiente transmissão de informações, criando condições para uma maior interação entre os sujeitos envolvidos num espaço fluido e dinâmico que permite a ação, a participação, a livre problematização, bem como a liberdade de expressão.

Através das TD, como tablets, Ipod, máquina digital, data show, lousa digital, Iphone, computador conectado à internet, é possível promover mudanças na prática docente, compreendo a relação do ensinar aprendendo e de aprender ensinando. Com a inserção destes recursos na educação, um leque de possibilidades se abre, para que não reproduzamos da mesma forma um conteúdo ou uma atividade como seria sem os mesmos, pois segundo Araújo (2007, p. 527),

a incorporação dos computadores na educação não pode ser mera repetição dos cursos tradicionais ou aulas, se ela estiver ainda centrada na superada e tradicional concepção das tecnologias educacionais associadas às práticas de instruções programadas de algumas décadas atrás, tão conhecidas dos educadores.

Com a simples presença das TD em sala de aula, o papel do professor neste contexto de ensino e de aprendizagem precisa ser o de questionar, confrontar ideias, debater criticamente e 


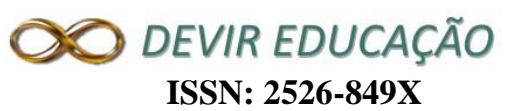

ressignificar as informações com os alunos, possibilitando-lhes a chance de se articularem em grupos cada vez mais específicos e numerosos no conjunto de valores que compõe o seu universo.

O professor necessita compreender a importância da utilização das TD em suas aulas, na busca de estratégias didáticas que possibilitem reduzir os problemas existentes, tais como: uma formação precária para o seu uso, políticas públicas que garantam uma formação permanente adequada a cada realidade, carência de apoio técnico e pedagógico nas escolas, poucos computadores disponíveis para o grupo de alunos, uma internet com velocidade adequada e a conscientização dos gestores no apoio aos professores para o desenvolvimento das suas atividades na temática apresentada.

Levando-se em conta tal problemática, é pertinente, seja em ambientes tradicionais de ensino ou em espaços contemporâneos, que professor e aluno trabalhem com autonomia e criticidade no uso das TD, mostrando-se dispostos a correr o risco de acertar e errar, inovar e conhecer, vencer e superar o que lhes é proposto, considerando que estas mídias sejam elementos presentes no seu cotidiano.

\section{Itinerário metodológico: tecendo os fios}

Os caminhos metodológicos são percursos que auxiliam pesquisadores na condução do estudo e tem como finalidade buscar, a princípio, possíveis respostas para questionamentos e inquietações afloradas por seus condutores. Nesse momento do estudo, a partir dos problemas prévios determinados, seus pesquisadores desejam alcançar por meio das etapas prédeterminadas alcançar e satisfazer seus problemas e seus objetivos. Para Oliveira (2015, p.100)

\footnotetext{
a pesquisa como um processo criativo deve ser identificada pela exploração e identificação de múltiplas perspectivas que buscam a compreensão do fenômeno, sejam elas positivistas, construtivistas, interacionistas ou outras, implicando habilidades metodológicas mínimas em termos de saber montar propostas dotadas de alguma cientificidade, em particular a capacidade de argumentar.
}

Diante dessa abordagem, acreditamos que para o desenvolvimento dos estudos, faz-se necessário, traças caminhos produtivos capazes de identificar e explorar possibilidades que levem seus pesquisadores à caminhos que os façam pensar e argumentar de forma crítica e 


\section{Q DEVIR EDUCAÇÃO \\ ISSN: 2526-849X}

construtiva os problemas prévios apresentados. Trata-se de um estudo de cunho qualitativo numa abordagem exploratória (CRESWEL, 2010).

A pesquisa foi realizada com 21 professores do Estado de Alagoas que atuam nos anos iniciais e finais do Ensino Fundamental e Ensino Médio em instituições públicas e/ou provadas, distribuídas em 8 cidades do estado. A participação dos professores ocorreu por meio de um questionário online disponibilizado e compartilhado na Web.

Com a finalidade de preservar o sigilo das identidades dos sujeitos, utilizamos o padrão P1, P2, P3, P4, ... para fazer referência às falas dos professores.

Durante todo o processo da pesquisa, foi necessário criar um espaço dialético entre os sujeitos envolvidos, para que fosse possível identificar, a partir das avaliações contínuas realizadas ante os desafios constantes e postos neste cenário da pandemia.

O questionário online utilizado permitiu aos pesquisadores, ações e compreensões dos desafios e aprendizados no uso das TD frente ao contexto da pandemia, tomando como base os escritos/achados e a incorporação crítica dos diferentes pensamentos e posicionamentos de seus interlocutores.

Do corpus coletado emergiram as categorias de análise: estratégias didáticas e TD, e em seguida foram estudadas e analisadas por meio do método de análise textual discursiva (MORAES; GALIAZZI, 2016).

Por fim, o caminhar metodológico da pesquisa é flexível, compreendendo que ao lado da coleta de dados outros elementos foram dando vida à interpretação das informações, bem como outros procedimentos potencializaram a análise dos dados, a fim de garantir o resguardo dos objetivos pretendidos pela pesquisa, buscando analisar quais estratégias didáticas foram utilizadas por professores do estado de Alagoas frente ao contexto pandêmico causado pelo novo coronavírus no Ensino Remoto Emergencial, mediado, especialmente, pelas TD.

\section{Estratégias didáticas no Ensino Remoto Emergencial (ERE): afinal, quais desafios e aprendizados?}

Os docentes foram convidados a fornecer informações sobre os recursos didáticos e suas estratégias didáticas realizadas durante o período da Pandemia no contexto do ERE.

A curiosidade epistemológica em conhecer e tecer reflexões sobre as estratégias didáticas ERE em função da pandemia de Covid-19 implicou na realização desta pesquisa na

Revista Devir Educação, Lavras-MG. Edição Especial, p.323-340, Set./2021. 
qual apresentamos os resultados e discussões, elencados a partir das respostas dos professores participantes.

Como demonstra o quadro 1 , os recursos que foram mais utilizados por professores durante o momento das aulas remotas são:

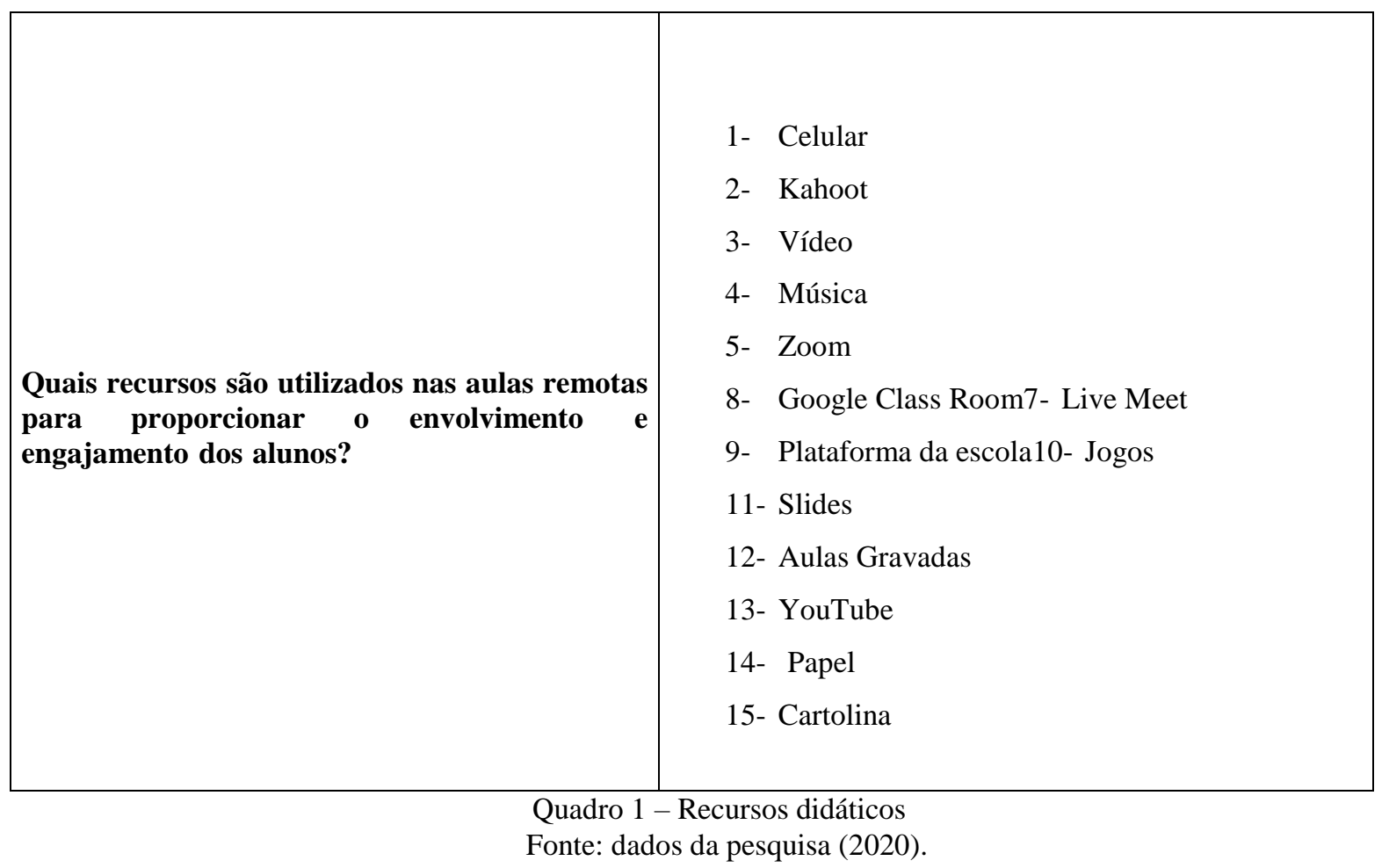

O quadro 1 apresentado acima mostra os recursos que foram usados por professores em tempos de aulas remotas, sem apresentar a frequência que eles foram usados. Para observamos a frequência utilizaremos o minerador de palavras Sobke para mostrar a intensidade que os recursos foram usados como mostra a figura 1.

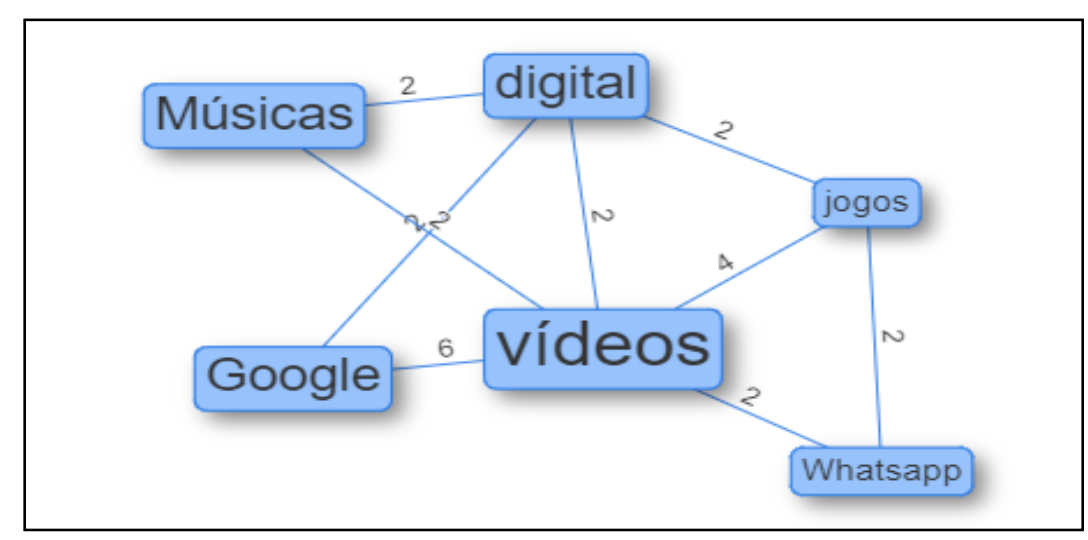

Revista Devir Educação, Lavras-MG. Edição Especial, p.323-340, Set./2021. 


\section{QO DEVIR EDUCAÇÃO \\ ISSN: 2526-849X}

Figura 1 - Mineração dos recursos didáticosS

Fonte: dados da pesquisa (2020)

Diante da mineração apresentada na figura 1 , podemos observar que os recursos que aparecem com mais frequência são os vídeos, músicas, jogos e WhatsApp. Frente ao cenário atual que os contextos educacionais passam, exigem dos professores recursos que os auxiliem em momentos de aulas remotas, e a partir da mineração dessas palavras, podemos verificar que os professores puderem usar os recursos tecnológicos que já fazem parte do cotidiano dos estudantes, tais como, vídeos, música, WhatsApp e jogos. A seguir no quadro 2 relatamos como o professor utilizou esses recursos em suas aulas:

\begin{tabular}{|c|c|}
\hline \multirow{6}{*}{$\begin{array}{l}\text { Quais são as estratégias didáticas } \\
\text { utilizadas durante as aulas remotas } \\
\text { para os processos de ensino e de } \\
\text { aprendizagem do conteúdo planejado? }\end{array}$} & $\begin{array}{l}\text { A1: Diálogo, espaço para a criança se expressar. Deixar que eles } \\
\text { leiam as atividades e digam suas respostas. Desenvolver jogos que } \\
\text { joguem de três em três. Manter a organização como se estivesse } \\
\text { jogando. }\end{array}$ \\
\hline & $\begin{array}{l}\text { A2: Observar o desenvolvimento do aluno, propondo atividades } \\
\text { que instiguem a criatividade e seus conhecimento previamente } \\
\text { adquirido. Partindo do conhecimento que os alunos já detém } \\
\text { inserir novos conhecimentos. }\end{array}$ \\
\hline & $\begin{array}{l}\text { A3: Criei uma ferramenta intitulada MatEJAZap para ser } \\
\text { utilizada com alunos da modalidade EJA Médio com objetivo } \\
\text { de facilitar o ensino e aprendizagem; a ferramenta é intuitiva e } \\
\text { facilita o acesso a conteúdos e atividades atravésde arquivos em } \\
\text { PDF e vídeos. }\end{array}$ \\
\hline & $\begin{array}{l}\text { A4: Prender a atenção dos alunos por meio da abordagem e dos } \\
\text { recursos, despertando seu } \quad \text { interesse, } \\
\text { questionamentos acerca do conteúdo em questão. }\end{array}$ \\
\hline & $\begin{array}{l}\text { A5: Utilizar exemplos práticos, mostrar objetos que se } \\
\text { relacionam aos conteúdos: relógio, bolas (corpos redondos), } \\
\text { caixas(poliedros) e tudo mais que ajudem a relacionar e } \\
\text { potencializar conhecimento. }\end{array}$ \\
\hline & $\begin{array}{l}\text { A6: Envio vídeos- aulas, indicação de sites, links, demonstro } \\
\text { atividades práticas, solicito desafios, jogos e simulações, } \\
\text { problematização, brain breaks e criação. }\end{array}$ \\
\hline
\end{tabular}




\section{OO DEVIR EDUCAÇÃO \\ ISSN: 2526-849X}

\begin{tabular}{|c|c|c|}
\hline & & $\begin{array}{l}\text { A7: Interação por meio de perguntas, propostas de leitura, escrita e } \\
\text { oralidade por meio de vídeos gravados pelos próprios alunos, com } \\
\text { a participação da família. }\end{array}$ \\
\hline
\end{tabular}

Quadro 2 - Estratégias didáticas

Fonte: dados da pesquisa (2020).

A partir dos dados observados no quadro 2 apresentado anteriormente, podemos verificar que os professores buscavam inserir em suas aulas recursos que pudessem proporcionar a interação os alunos em suas aulas como mostra a fala do professor A7. Esse momento de envolvimento do aluno com as atividades proposta faz-se necessário no atual contexto, principalmente no sentido de poder proporcionar a participação ativa dos alunos. O quadro 3 apresentado a seguir nos mostra os principais desafios enfrentados por professores durante suas aulas.

\begin{tabular}{|c|c|}
\hline & A1: Não ter equipamento necessário para realizar as aulas \\
\hline & $\begin{array}{l}\text { A2: Conseguir ganhar a atenção dos alunos, pois se na aula } \\
\text { presencial são dispersos, nas atividades on-line não seria } \\
\text { diferente. Entretanto, o desafio maior é não poder atingir da } \\
\text { mesma forma os alunos de zona rural e alguns da cidade. Pois } \\
\text { o acesso à tecnologia ainda é um problema. Nem todos têm } \\
\text { recursos para se beneficiar com celular e internet. }\end{array}$ \\
\hline & $\begin{array}{l}\text { A3: A privacidade da família do professor e do aluno, a } \\
\text { adaptação e limitação das crianças frente ao uso das } \\
\text { plataformas e o pouco tempo de atenção concentrada. }\end{array}$ \\
\hline $\begin{array}{c}\text { Quais são os principais desafios frente a } \\
\text { utilização desses recursos nos momentos } \\
\text { das aulas remotas? }\end{array}$ & $\begin{array}{l}\text { A4: Atingir a todos os alunos, visto que, alguns alunos da } \\
\text { rede pública principalmente da zona rural por não terem } \\
\text { acesso a internet. Por isso, precisamos desenvolver novas } \\
\text { estratégias o que torna o trabalho menos cansativo e exaustivo. } \\
\text { Fora a pressão psicológica para atingir a maioria dos alunos e } \\
\text { possibilitar a aprendizagem nesse novo formato } \\
\text { provocados pelo distanciamento. }\end{array}$ \\
\hline & $\begin{array}{l}\text { A5: A maior dificuldade é alfabetizar os alunos de forma } \\
\text { remota, mas tenho feito ficha de leitura e outros materiais } \\
\text { para tentar alcançar nossos pequenos. }\end{array}$ \\
\hline & $\begin{array}{l}\text { A6: Contato com os alunos, pois a minoria está sendo } \\
\text { atendida e, por vezes, o contato com essa minoria édificultoso, } \\
\text { devido o sinal de Internet destes. }\end{array}$ \\
\hline & $\begin{array}{l}\text { A7: O celular com pacote de dados suficiente; o celular adequado } \\
\text { com aplicativo WhatsApp; acesso a internet; dificuldade de uso do } \\
\text { aplicativo por não ter domínio. }\end{array}$ \\
\hline
\end{tabular}




\begin{tabular}{|l|l|}
\hline \multirow{2}{*}{} & A8: A dificuldade em perceber as dúvidas do aluno. \\
\cline { 2 - 3 } & $\begin{array}{l}\text { A9: Falta de habilidade para trabalhar com a tecnologia e a falta } \\
\text { de acesso por parte dos alunos e a colaboração dos pais. }\end{array}$ \\
\hline
\end{tabular}

Quadro 3 - Desafios nas aulas

Fonte: dados da pesquisa (2020).

Diante dos resultados apresentados podemos observar quais foram dificuldades apresentados pelos professores durante a aula e podemos destacar o acesso dos alunos as plataformas de ensino em especial para alunos da zona rural, como pode ser visto na fala do professor A4 "Atingir a todos os alunos, visto que, alguns alunos da rede pública principalmente da zona rural por não terem acesso a internet". Um outro fator observado foi a falta de internet, bem como dificuldades em alfabetizar nesse modelo de ensino visto que os alunos ficam dispersos como afirma o professor A2 "Conseguir ganhar a atenção dos alunos, pois se na aula presencial são dispersos, nas atividades on-line não seria diferente". Podemos observar, a partir dos dados coletados, a falta de capacitação para que os professores pudessem atuar em aulas remotas ocasionando a ausência de habilidades para trabalhar com as tecnologias.

A seguir no Quadro 4, apresentamos os desafios lançados por seus professores aos alunos.

\begin{tabular}{|c|c|}
\hline \multirow{5}{*}{$\begin{array}{c}\text { Quais são os desafios lançados por você, } \\
\text { professor(a), aos seus alunos, como atividade de } \\
\text { casa? }\end{array}$} & $\begin{array}{l}\text { A1: Leitura e produção de textos com suporte em } \\
\text { imagens ou vídeos, produções artísticas e mensagem } \\
\text { crítico-reflexivas. }\end{array}$ \\
\hline & $\begin{array}{l}\text { A2: Solicito que os alunos realizem as atividades dos } \\
\text { módulos, que façam os jogos, tirem fotos dos } \\
\text { momentos. Também pedimos que elaborem textos, } \\
\text { façam desenhos para serem mostrados naaula online } \\
\text { e respondam algum quiz na plataforma. }\end{array}$ \\
\hline & $\begin{array}{l}\text { A3: Elaboração de jogos, quadrinhos, memes e } \\
\text { paródias. Interpretação de músicas, vídeos e imagens. } \\
\text { Confecção de vídeos, materiais manipuláveis e } \\
\text { textos. }\end{array}$ \\
\hline & $\begin{array}{l}\text { A4: Temos proposto diversas brincadeiras antigas, } \\
\text { utilizando os espaços dentro de casa, produção de } \\
\text { texto (como uma carta para umamigo que está com } \\
\text { saudades), gravações desses momentos e outros. }\end{array}$ \\
\hline & $\begin{array}{l}\text { A5: Resenhas críticas a partir de livros ou filmes, nas } \\
\text { aulas de Redação. Propostas de produção de } \\
\text { releitura de obras de arte, nas aulas de Arte. }\end{array}$ \\
\hline
\end{tabular}

Revista Devir Educação, Lavras-MG. Edição Especial, p.323-340, Set./2021. 


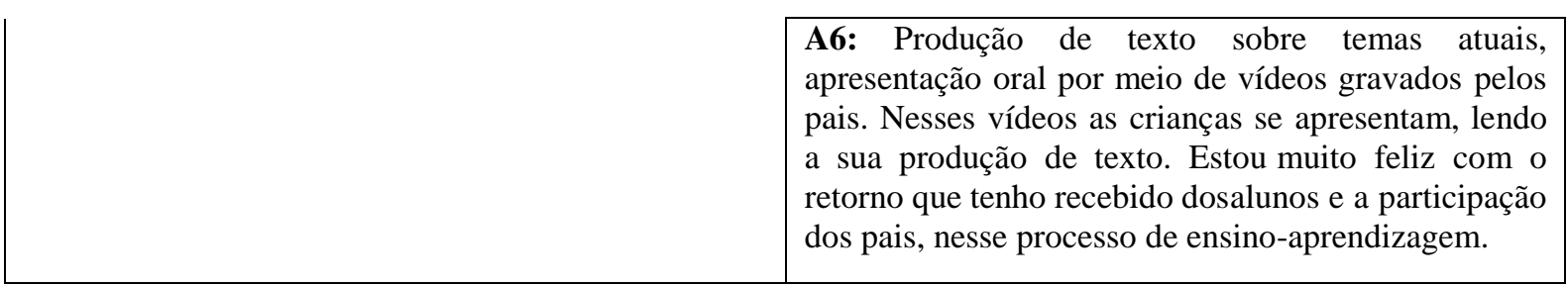

Quadro 4 - Desafios lançados pelos professores aos alunos

Fonte: dados da pesquisa (2020)

Os dados apresentados no quadro 4, observamos que os professores proporcionavam aos seus alunos atividades que estivessem dentro das suas possibilidades, como mostra a solicitaçãode uma produção de texto e depois compartilhado com a professora como mostra a fala A6:

Produção de texto sobre temas atuais, apresentação oral por meio de vídeos gravados pelos pais. Nesses vídeos as crianças se apresentam, lendo a sua produção de texto. Estou muito feliz com o retorno que tenho recebido dos alunos e a participação dos pais, nesse processode ensino-aprendizagem.

Outro ponto que devemos observar é a importância da realização dessa tarefa que gera felicidade na professora. No quadro 5 apresentado a seguir mostramos os conhecimentos e habilidades que horas desenvolvidos pelos professores durante esse período. 


\begin{tabular}{|c|c|}
\hline \multirow{8}{*}{$\begin{array}{l}\text { O que vemos hoje são professores } \\
\text { angustiados, tentando produzir conteúdos } \\
\text { em formatos até então não [ou pouco] } \\
\text { explorados, sem a certeza de sua efetividade e } \\
\text { se alcançarão todo o seu alunado. A partir } \\
\text { desse contexto, quais conhecimentos e } \\
\text { habilidades foram necessários para a } \\
\text { elaboração das suas aulas e dos materiais } \\
\text { digitais? }\end{array}$} & $\begin{array}{l}\text { A1: De início, o interesse de mantê-los de mente ativa. Por } \\
\text { conseguinte, desenvolver habilidades para se familiarizar } \\
\text { com uma câmera (a qual não sou muito fã), criar } \\
\text { estratégias de desenvolver diversas atividades que não } \\
\text { sejam de conteúdos programáticos,etc. }\end{array}$ \\
\hline & $\begin{array}{l}\text { A2: Habilidades sociais, emocionais, criativas e } \\
\text { cognitivas. Interpretação e manipulação de materiais e } \\
\text { textos. }\end{array}$ \\
\hline & $\begin{array}{l}\text { A3: Primeiramente conhecer a turma e propor novos } \\
\text { desafios tanto para os alunos quanto para a professora.Não é } \\
\text { fácil, nunca foi, existe uma angústia no que diz respeito a } \\
\text { qualidade do meu trabalho e se isso está sendo proveitoso } \\
\text { pelos alunos. }\end{array}$ \\
\hline & $\begin{array}{l}\text { A4: Habilidade de uso da internet, Habilidade em viver em } \\
\text { coletividade pela web. Busca de conhecimento, rever todo } \\
\text { o planejamento, criatividade, foi necessário se reinventar. }\end{array}$ \\
\hline & $\begin{array}{l}\text { A5: Um conhecimento mínimo do funcionamento de } \\
\text { tecnologias e redes sociais, bem como gravação e detalhes } \\
\text { como som e luz para a melhor qualidade dosvídeos durante } \\
\text { as aulas. }\end{array}$ \\
\hline & $\begin{array}{l}\text { A6: Conhecimento básico sobre plataforma Moodle, } \\
\text { editores de textos, de imagem, de vídeo, PowerPoint, } \\
\text { aplicativo de captura de tela, loom, etc. }\end{array}$ \\
\hline & $\begin{array}{l}\text { A7: Minhas primeiras experiências foram assustadoras } \\
\text { pois não tinha o domínio das ferramentas e não consegui } \\
\text { conduzir a aula, as crianças falavam ao mesmo tempo, } \\
\text { compartilhavam ou riscavam a tela. Após esse choque de } \\
\text { realidade, me aprofundei na utilização do Zoom com a } \\
\text { ajuda de colegas e hoje estou gravando vídeoaulas e dando } \\
\text { cursos sobre essa ferramenta. Busquei pesquisar mais sobre } \\
\text { gravação de vídeos, recursos digitais e sites interativos, } \\
\text { Ambientes virtuais de aprendizagem e metodologias } \\
\text { ativas com as tecnologias. Atualmente faço formações para } \\
\text { outros educadores sobre esses temas. }\end{array}$ \\
\hline & $\begin{array}{l}\text { A8: Se colocar no lugar do aluno e perceber que são } \\
\text { crianças, que estão ansiosas e que gostam denovidades. Na } \\
\text { elaboração de uma aula, sempre que possível tento } \\
\text { acrescentar algo que envolva o emocional do aluno. Como } \\
\text { uma música para animar ou acalmar a mente. Peço que os } \\
\text { alunos fiquem de pé, para exercitar o corpo com uma } \\
\text { música. }\end{array}$ \\
\hline
\end{tabular}

Quadro 5 - Conhecimentos e habilidades desenvolvidos por professores Fonte: dados da pesquisa (2020)

Podemos observar no quadro 5 apresentado acima os saberes e habilidades mobilizados pelos professor em sua prática docente, notamos que incialmente para o desenvolvimento das aula foi uma realidade totalmente diferente das vivenciadas em 


\section{OO DEVIR EDUCAÇÃO \\ ISSN: 2526-849X}

contextos presenciais, entretanto, podemos relatar que essas ações trouxe algumas habilidade para os professores, tais como: produção de vídeo, emocionais, social, verificamos que os professores puderem rever sua prática e buscar recursos que pudessem proporcionar o desenvolvimento tanto do aluno como do professor, essa situação pode ser verificada na fala do professor A7:

Minhas primeiras experiências foram assustadoras pois não tinha o domínio das ferramentas e não consegui conduzir a aula, as crianças falavam ao mesmotempo, compartilhavam ou riscavam a tela. Após esse choque de realidade, me aprofundei na utilização do Zoom com a ajuda de colegas e hoje estou gravando vídeoaulas e dando cursos sobre essa ferramenta. Busquei pesquisar mais sobre gravação de vídeos, recursos digitais e sites interativos, Ambientes virtuais de aprendizagem e metodologias ativas com as tecnologias. Atualmente faço formações para outros educadores sobre esses temas.

Diante do que foi apresentado, podemos verificar que os momentos de aulas remotas trouxeram desafios e reflexões dos professores para sua prática, bem como, o desenvolvimento de novas habilidades.

No quadro 6 apresentamos os desafios evidenciados durante essa prática:

\begin{tabular}{|c|c|}
\hline \multirow{8}{*}{$\begin{array}{c}\text { Quais foram as principais dificuldades } \\
\text { enfrentadas por você neste cenário? }\end{array}$} & $\begin{array}{l}\text { A1: A possibilidade de Dinamizar a apresentação } \\
\text { do conteúdo. }\end{array}$ \\
\hline & A2: A interação dos alunos. \\
\hline & $\begin{array}{l}\text { A3: Angustia psicologia, desenvolvimento de um } \\
\text { trabalho com qualidade e que meus alunos gostem. }\end{array}$ \\
\hline & $\begin{array}{l}\text { A4: As gravações, por não está preparada para tal, mas } \\
\text { busquei encontrar caminhos para enfrentar os } \\
\text { desafios e tentar alcançar nossos alunos. }\end{array}$ \\
\hline & $\begin{array}{l}\text { A5: O contato com os alunos. A falta de contato com } \\
\text { a maioria e o descaso, diga-se assim, que alguns pais } \\
\text { que tenho contato, estão fazendo em relação a } \\
\text { realização das atividades, faz todo esse momento se } \\
\text { tornar frustrante, angustiante. }\end{array}$ \\
\hline & $\begin{array}{l}\text { A6: O funcionamento da internet, já que estou } \\
\text { isolada em uma zona rural. }\end{array}$ \\
\hline & A7: A compreensão das famílias. \\
\hline & A8: Editar vídeos. \\
\hline
\end{tabular}




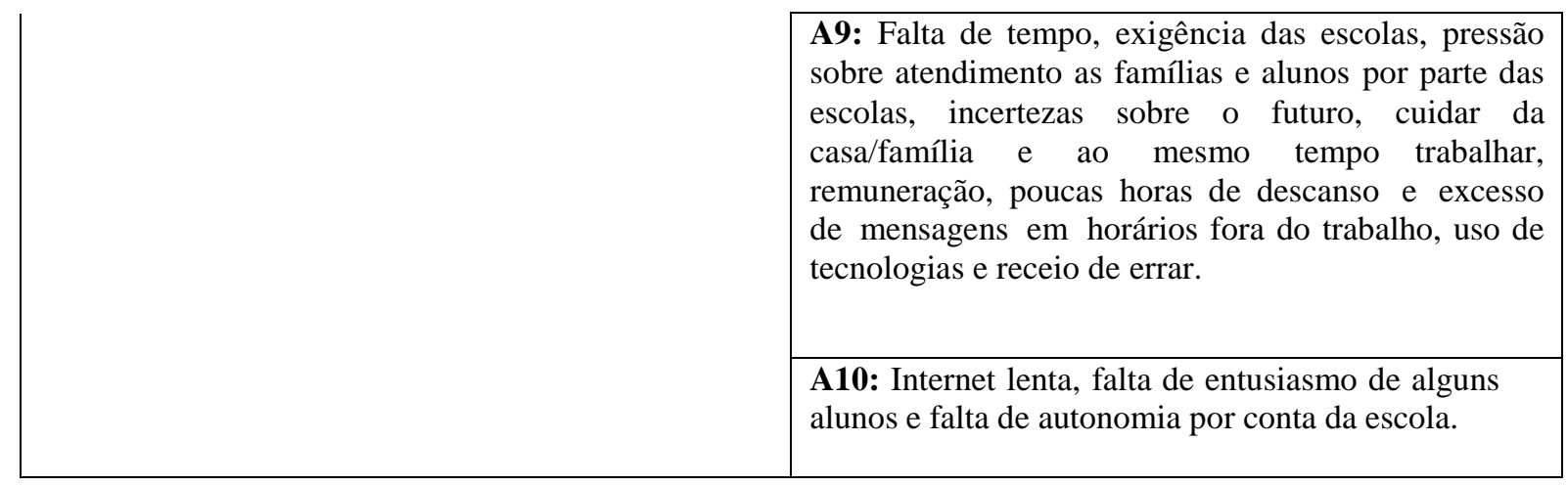

Quadro 6 - Dificuldades

Fonte: dados da pesquisa (2020)

O quadro 6 apresenta as principais dificuldades oriundas das aulas remotas, essas ações estão relacionadas com a falta de internet, de preparação para produção de gravações e edição de vídeos, a incompreensão das famílias diante dessas dificuldades, as cobranças realizadas pelas instituições relacionadas com os atendimentos às famílias e alunos e a desvalorização profissional como mostra a fala do professor A9:

Falta de tempo, exigência das escolas, pressão sobre atendimento as famílias e alunos por parte das escolas, incertezas sobre o futuro, cuidar da casa/família e ao mesmo tempo trabalhar, remuneração, poucas horas de descanso e excesso de mensagens em horários fora do trabalho, uso de tecnologias e receio de errar.

Podemos observar, também, a falta de contato com os estudantes ocasionadas por esse modelo remoto e, por vez, essa situação nos faz refletir a respeito dessa situação. Outro ponto que se destaca e a necessidade de formação dos professores para atuar nesse formato, visto que não estavam preparados para essa situação, e isso nos faz re(pensar) em estratégias que possam proporcionar a capacitação desses profissionais mesmo em tempo remotos.

\section{Considerações finais}

Esta pesquisa problematizou as estratégias didáticas de professores em tempos de Covid-19, por meio dos relatos, que mostraram a realidade no âmbito de uso de recursos tecnológicos, suas características e concepções, buscando na literatura bases legais para promover a reflexão sobre a temática proposta. 
Nessa investigação percebemos que os professores, no âmbito das estratégias didáticas no ERE, podem conviver cada vez mais de perto com as potencialidades desses artefatos tecnológicos. Em contrapartida, ainda há uma desatualização tecnológica por parte dos envolvidos para lidar com essa questão. As formações para lidar com esse tipo de recursos ainda não são suficientes para fazer com que professor se sinta à vontade para navegar, interagir e proporcionar práticas inovadoras no processo de ensino e de aprendizagem.

Necessita-se de olhares que articulem, através das TD, um espaço para o compartilhamento de saberes e experiências, e que facultem aos sujeitos posturas investigativas e multiplicadoras de concepções que permitam exercer uma posição crítica ante a sua realidade, interrogando-a, buscando alternativas teóricas e práticas diante de suas problemáticas.

\section{Referências}

ALMEIDA, M. E. Inclusão digital do professor: formação e prática pedagógica. São Paulo: Articulação, 2004.

ALMEIDA, M. E; VALENTE, J. A. Tecnologias e currículo: trajetórias convergentes ou divergentes? São Paulo: Paulus, 2011.

ARAÚJO, M. M. O pensamento complexo: desafios emergentes para a educação on-line.

Revista Brasileira de Educação, v. 12, n. 36, p. 515-529, set./dez. 2007.

BORBA, M. C. Tecnologias informáticas na educação matemática e reorganização do pensamento. In: BICUDO, M. A. V. (Org.). Pesquisa em educação matemática: concepções \& perspectivas. São Paulo: Unesp, p.285-295, 1999.

CASTELlS, M. A sociedade em rede. São Paulo: Paz e Terra, 1999. v. 1.

CRESWELL, J. W. Projeto de pesquisa: métodos qualitativo, quantitativo e misto. 3. ed. Porto Alegre: Artmed, 2010.

LEMOS, A. Cibercultura: tecnologia e vida social na cultura contemporânea. Porto Alegre: Sulina, 2002.

MORAES; R.; GALIAZZI, M. C. Análise textual discursiva. 3. ed. Ed. Unijuí, 2016.

OLIVEIRA, C. A. de. Estratégias didáticas nos processos de ensino e de aprendizagem em Matemática no mundo digital virtual em 3D Open Sim. (Tese de Doutorado). Universidade Federal de Alagoas, Maceió, 2015.

OLIVEIRA, S. da S.; SILVA, O. S. F.; SILVA, M. J. de O. (2020). Educar na incerteza e na 
urgência: implicações do ensino remoto ao fazer docente e a reinvenção da sala de aula. Disponível em: https://periodicos.set.edu.br/educacao/article/view/9239. Acesso em: 11 jun. 2021.

SANTAELLA, L. A ecologia pluralista da comunicação: conectividade, mobilidade, ubiquidade. São Paulo: Paulus, 2010.

SANTAELLA, L. Culturas e artes do pós-humano: da cultura das mídias à Cibercultura. São Paulo: Paulus, 2003.

SANTOS, E. Pesquisa-formação na cibercultura. Santo Tirso, Portugal: Whitebooks, 2014.

VALENTE, J. A. As tecnologias digitais e os diferentes letramentos. Porto Alegre: Pátio, 2007.

VALENTE, J. A. Diferentes usos do computador na educação. 2004. Disponível em: <http://www.educacaopublica.rj.gov.br/biblioteca/index.php>. Acesso em: 13 mar. 2013.

Recebido em: 21-07-21

Aprovado em: 30-08-21 